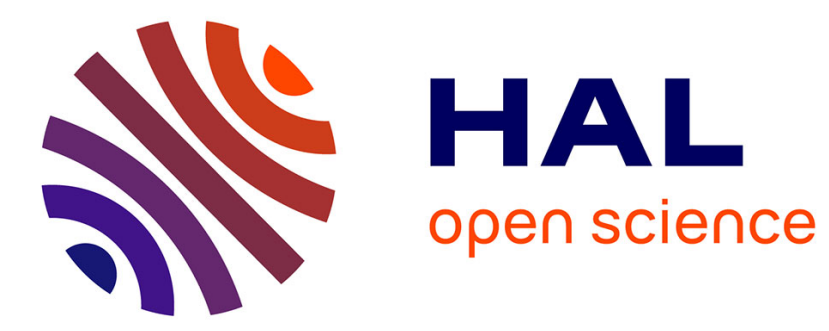

\title{
Individual and Social Temporalities in American Sociology (1940-2000)
}

Vincenzo Cicchelli, Catherine Pugeault-Cicchelli, Maurizio Merico

\section{To cite this version:}

Vincenzo Cicchelli, Catherine Pugeault-Cicchelli, Maurizio Merico. Individual and Social Temporalities in American Sociology (1940-2000). Time \& Society, 2006, 15 (1), pp.141-158. 10.1177/0961463X06061335 . hal-00571004

\section{HAL Id: hal-00571004 \\ https://hal.science/hal-00571004}

Submitted on 1 Mar 2011

HAL is a multi-disciplinary open access archive for the deposit and dissemination of scientific research documents, whether they are published or not. The documents may come from teaching and research institutions in France or abroad, or from public or private research centers.
L'archive ouverte pluridisciplinaire $\mathbf{H A L}$, est destinée au dépôt et à la diffusion de documents scientifiques de niveau recherche, publiés ou non, émanant des établissements d'enseignement et de recherche français ou étrangers, des laboratoires publics ou privés. 


\title{
Time
}

Society

\section{Research Note Individual and Social Temporalities in American Sociology (1940-2000)}

\section{Vincenzo Cicchelli, Catherine Pugeault-Cicchelli and Maurizio Merico}

\begin{abstract}
This article is based on the analysis of 259 titles of articles selected from four American sociological journals (the American Journal of Sociology, Social Forces, the American Sociological Review and Social Problems), over a period of 60 years (1940-2000). These titles contain key words such as age(s), generation(s), life cycle and life course, as well as a group of words that identify the purpose of each specific article. The lexical analysis of the data gathered in this way allows us to observe how various orientations, themes and objects of research are encoded in the titles. Comparing how each of these terms is used shows the way in which sociological reasoning has integrated different perspectives on individual and social temporalities. We have established that each of the four different perspectives considered refers to an exclusive lexical repertoire, to themes of differentiated research that belong to a specific historical period. KEY WORDS • age $\bullet$ generation $\bullet$ life cycle $\bullet$ life course $\bullet$ temporalities
\end{abstract}

\section{Introduction}

In pursuit of legitimacy, social scientists frequently refer to the long-standing nature of their area of inquiry, emphasizing the early contributions made by their

Time \& Society copyright $(C) 2006$ SAGE (London, Thousand Oaks, CA and New Delhi) VOL. 15 No. 1 (2006), pp. 141-158 0961-463X DOI: 10.1177/0961463X06061335 
predecessors. This attitude is particularly apparent for certain objects of research, such as the family, urbanization, industrialization and religion, and for theoretical perspectives such as social ties, the relationship between the individual and institutions, social change and so on. Handbooks, the powerful vectors of production and reproduction of legitimacy, record the work carried out during the long history of the discipline, trying to bind them to the founding fathers' work. Such is not the case for the dimensions of individual and social temporalities, such as age, generation, the life course and the life cycle. In this respect, one might say that sociological interest developed much later (Saraceno, 1986; Galland, 1991; Bergmann, 1992) than in psychology (Demos and Demos, 1969; Dubas et al., 2003; Kett, 2003).

It was essentially after the Second World War that scholars gradually highlighted three overlapping dimensions: (a) the biographical trajectory or individual time; (b) change within institutions and groups, or institutional time; (c) social transformation or historical time. This article describes some sections of this recent history, showing how the above dimensions have little by little been introduced to sociological reasoning springing from four perspectives, namely the ages of life, generations, life cycle and life course. The results presented refer to the American sociological literature from 1940 to 2000. Based on Correspondence Analyses of a lexical corpus of article titles gathered from sociological journals, these results allowed us to approach the literature on temporalities (with specific attention to the dimensions of age, generation, the life cycle and the life course) through the way in which scientific communication is historically determined. ${ }^{1}$

\section{Communication of Scientific Knowledge in Four American Journals}

Historically, sociological works concerning age and the life course as dimensions of individual and social temporality have mostly developed in the United States. American supremacy is indisputable, as revealed by the treatises, review articles, research reports and symposia relating to the period that we have studied (1940-2000). The American sociological literature considered has allowed us to observe, probably more clearly than in the European case, the structure of research on age, generation, the life cycle and the life course. It would be naïve to take into consideration the whole of the American literature on these dimensions of temporality. In order to avoid this difficulty, we have chosen to favour an institutional approach.

We sampled the research domain by analysing four journals that are a genuine showcase of American sociology: the American Journal of Sociology, Social Forces, the American Sociological Review and Social Problems. These journals represent the most legitimated means of diffusion and codification of sociologi- 
cal knowledge. Then a subgroup composed of the titles of articles published in these journals and including key words such as Age(s), Aged, Generation(s), Generational, Intergenerational, Life Course, Life Cycle(s) was selected. ${ }^{2}$ The singular and the plural, the adjectives associated with the nouns were also taken into consideration. A corpus containing a total volume of 259 titles was gathered. The co-occurence of two relevant key words referring to different aspects of temporality (such as age, generation, the life cycle and the life course) was seldom observed, which is the first sign of the exclusivity of orientation. ${ }^{3}$

These titles chosen on the basis of the key words form a pertinent indicator that expresses the way in which the authors and the editorial boards of the journals wish to convey information. Although they cannot be reduced to an abstract of the articles that they relate to, the titles have persuasive effects. As performative acts, they can be considered as mediators between the author's intention, the filter of the editors and the state of the literature that encourages recourse to a concept, a theme of research or a dimension of temporality (as, in our analysis, age, generation, the life cycle and the life course).

These observations allow us to situate the contribution of our research, which scrutinizes primarily the way these four dimensions of temporality are presented within renowned channels of scientific communication. We do not deal with the analysis of the argumentation, with the theoretical references, or with mobilized methodologies. The objective consists in analysing the themes retained by the scientific community to deal with the issues of age, generation, the life cycle and the life course.

\section{The Lexical Repertoire Associated with Age, Generation, Life Cycle and Life Course}

What information is given by the titles of articles? The content analysis of the titles allows us to identify a lexicon, a dictionary that considers all of the significant units of the scientific language relevant to the four temporal approaches at a given time (Mounin, 1973). The corpus of the titles offers a sample of sociological language, of its words (adjectives, nouns) and of the rules necessary to establish a communication between the text and the reader. ${ }^{4}$ We have attempted to classify these words into lexical items with a certain consistency. Table 1 presents these groupings.

All the chosen titles exhibit at least one key word related to one of the temporal items. However, the content of the titles supplies much more information. Out of 100 occurrences, three-quarters display precision about scientific competence, social belonging, social stratification and employment, the family, socialization and identity, delinquency and its control and health.

Although there are many items, their classification yields a relatively concise 
repertoire. The words that display a scientific competence refer to a disciplinary scientific rhetoric. They underline the objectives to be pursued, place the author in a theoretical and academic debate and emphasize an explanatory aim. Next to the markers related to a dimension of temporality they represent the most important part of the repertoire, accounting for approximately 1 word out of 4 .

The belongings are many. They refer to groups, to collective, national, ethnic and sexual identities: 1 word out of 6 is concerned. On the other hand, more than 1 word out of 10 refers to social stratification, to employment and to the general socioeconomic context. The other items show percentages lower than 10: they correspond to specific themes rather than to core orientations in sociology (i.e. in the case of social belonging and stratification). Joined together, conjugal life and parenting, construction of individual identity and socialization processes (together with behaviours, attitudes, roles, satisfaction and selfachievement), delinquency and the social control of delinquency and health (with some non-classified words) constitute 1 occurrence out of 5. Therefore this repertoire reflects a strong hierarchy in the dissemination of sociological knowledge through article titles in the United States: the achievement of a scientific competence, social belonging and social stratification prevail over the link between the considered dimensions of temporality and the themes of family life, socialization, delinquency and health.

\section{The Links between the Words of the Lexicon}

In order to obtain the links between such words as age, generation, life cycle, life course and a group of words that form a lexical corpus, we have carried out a Correspondence Analysis within which the four dimensions of temporality are active variables. Each aspect of temporality refers to a consistent group of words. Figure 1 reveals four semantic fields. ${ }^{5}$

\section{The first opposition: age versus generation}

On the left of Figure 1, we have isolated the group of words linked to the generation temporality. The prefixes inter-, first-, second-and three refer to the studies that deal with the relations between generations. Through the omnipresent syntagm 'occupational mobility' (Goyder and Curtis, 1975), stress is placed on the study of social stratification and on class relations. The orientation remains rather general. In the journals, the sociology of generations equally enhances the value of a perspective sensitive to differences due to gender and to ethnic origins. ${ }^{6}$ The study of men's and women's or black and white people's mobility displays some common characteristics. The comparative examination of groups belonging to different generations precedes research on behaviour or attitude 
TABLE 1

Repertoire of thematic items of the lexical occurrences associated with the key words 'age', 'generation', 'life cycle' and 'life course' (in absolute terms and in \%)

\section{Items}

Occurrences

$\%$

Temporalities (age(s), cohort(s), generation (inter; first, second, three), life, life course, life cycle, time, young adult, youth, adult, adulthood, adolescent, old, old age, change, changing, transition, transformation, contemporary, early, continuity.)

Scientific competences (consequences, effects, impact, influence(s), approach, perspective, study, research, difference, differential, variations, distribution, pattern(s), population, size, analysis, experience, panel, comment, assessment, accounting, response, note, curve, statistical, test, rates, significance, independence, variable(s), adjustment, sequencing, comparison, explaining, understanding, factors, predictability, sociology, sociological, psychological, theory, model, formalization, hypothesis, case, method, characteristics, context, cross national, longitudinal, evidence, specific, relative.)

Belongings/membership (group(s), membership, friendship, relation(ship), cohesion, contact, bonds, association, organization, gangs, support, voluntary, participation (Subtotal: 83).

Geographical origins (country, city, neighbourhood) (Subtotal: 78). Sex, gender, female(s), women, male(s), man, men (Subtotal: 47). Black(s), negro, race, racial, ethnic, ethnicity, white(s), discrimination, segregation (Subtotal: 44).)

Stratification and employment (stratification, class, status, structure (s), (un)employment, labour, work, occupation, job, mobility, capital, income, earnings. Social, society, socioeconomic, economic, economy, sociopolitical.)

Family, conjugality and relatives (courtship, endogamy, sexual, dating, marital, marriage, cohabitation, divorce, mothers, fathers, parent(al), parenthood, children, daughters, sons, birth, fertility, family(ies), spouse, wives.)

Socialization and identity (attitudes, orientation, behaviour, defiance, involvement, achievement, attainment, preference, choice, values, norms, socialization, role, constraint, integration, education(nal), satisfaction.)

Delinquency, control of delinquency (crime, delinquent/ delinquency, police, deviance, prison, arrest, vandalism.)

Health (health, mental(health), illness, suicide, care.) 
patterns specific to each generation. The intersection between generation and the family implies references to socialization (Bengtson, 1975), to family support and mutual assistance (Lee et al., 1994).

To the right of the figure, we have identified words connected to the marker age. First of all, on a methodological level, the titles of these articles try to unravel the links between the effects of age, period and cohort. Many articles concentrate on this issue, such as those by Glenn (1976) or Palmore (1978). ${ }^{7}$ Concerning their content, emphasis is placed on a particular age group: the elderly. Many titles also refer to age at marriage, to the relations between legal offenders and age structure and to the relations between age and work satisfaction. Above all, the double reference to the general effects of age and sex is often found, starting from the title of the founding article by Parsons, 'Age and Sex in the Social Structure of the United States' (1942). This association appears in the titles of the main studies of intimate relationships (Lowrie, 1952), the mental problems of the elderly (Belknap and Friedsam, 1949), delinquency (Hindelang, 1971) and race, but also in more methodological works on how to carry out interviews (Benney et al., 1956).

\section{The second opposition: life cycle versus life course}

Figure 1 displays a second opposition. At the top, there is a group of words linked to the life cycle. More than for the previous two key words, the terms that surround this marker reveal a desire to analyse discontinuities and transitions between the different stages of life. The authors of the articles concerned pay attention, in particular, to the influence of life cycle transitions on membership of institutions and groups (such as, for example, associations (Knoke and Thomson, 1977; Rotolo, 2000) or religious denominations (Stolzenberg et al., 1995)).

However, one object of research is undoubtedly linked to the marker life cycle, and that is the family. Family cycle is raised to the rank of explanatory variable (Lansing and Kish, 1957) and has already been assessed in the sociological literature. Just as age and generation, life cycle takes into consideration the ethnic identity of the populations studied and the place where they live, which may be considered a novelty. On the other hand, compared to the other two key words, little attention is paid to stratification and it is only in terms of the occupational area that we can verify how well founded the approach might be (Leslie, 1961).

Finally, at the bottom of the figure, the items linked to the life course can be observed. Unlike for life cycle, the stress is here placed on the individual's life, as for example in the case of old age (Moen et al., 1992). The institutional dimension, present in the life cycle, is here replaced by a more relational approach that tends to compare adults and children. Where family cycles used to 


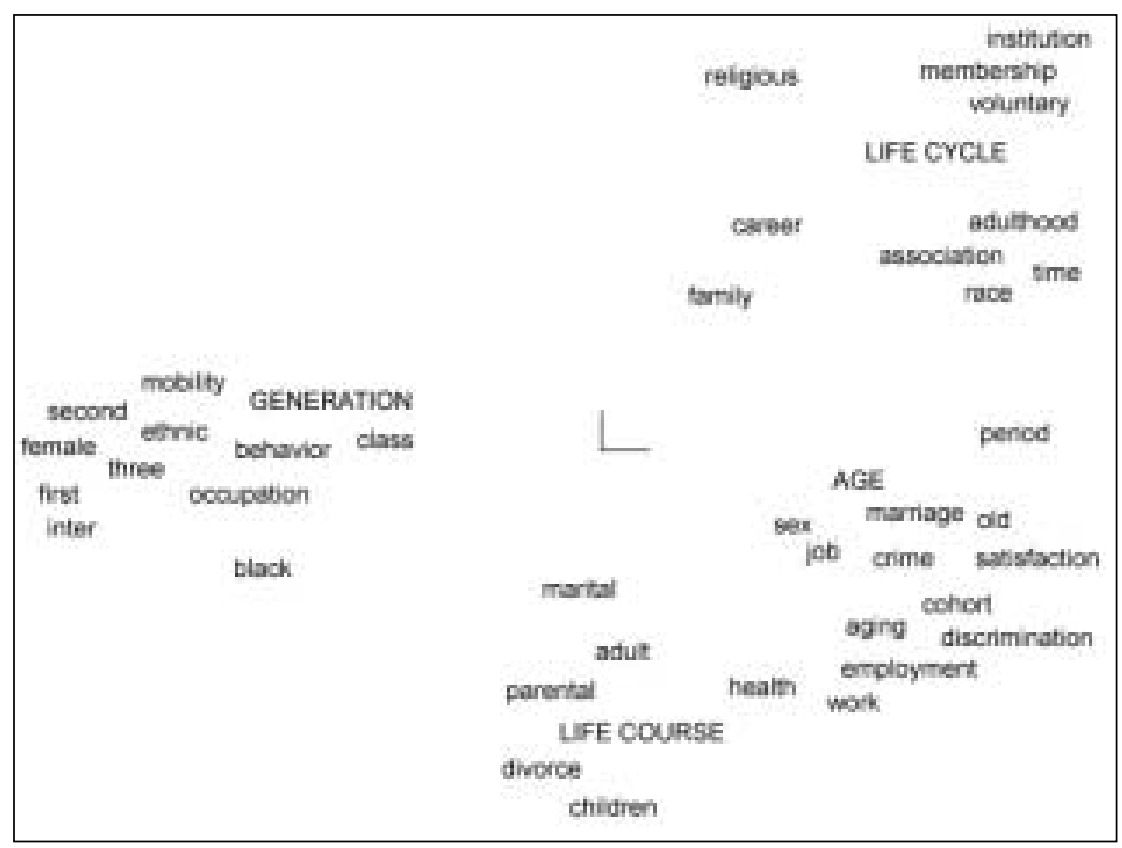

FIGURE 1

Relevant words associated with the considered temporalities

(Correspondence Analysis using the software Tri-deux 3.1

be found, there are now family actors at a crucial moment in their lives: divorce. The breaking-up of a marriage paves the way to studies on how to maintain contact between parents and children (Furstenberg et al., 1983) and on the consequences of this separation on younger children's health (Cherlin et al., 1998). Ethnic differences relate to the issue of discrimination (Thomas et al., 1994), whereas the issue of employment is broached only as regards married women's jobs (Treas and Widmer, 2000). Economic difficulties due to professional insertion problems have also been discussed (Mirowsky and Ross, 1999).

\section{The Words of the Lexicon through History}

The lexical links, when isolated, highlight some important questions. Concerning the family, one may wonder why research on age often deals with age at marriage, those on generations with mutual assistance within families, those on the life cycle with belonging to a family institution and, finally, why those on the 
life course are most often centred on divorce. As a matter of fact, the changes in words reveal changes in points of view under the cumulative effect of transformations of the social context and of the transformation of the sociological problematic. It is therefore important to pay attention to the dates of scientific production.

The Correspondence Analysis presented in Figure 2 allows us to understand the existing links between the age, generation, life cycle and life course markers and the historical dimension studied over 10-year periods. Thus, the decades play the role of active variables. ${ }^{8}$ The vocabulary of the considered dimensions of temporality is distributed according to a double opposition between the 1940s-50s and the 1990s on the one hand, and between the 1940s-50s and the 1970 s on the other. It has not been possible to associate a specific vocabulary to the 1960s and 1980s.

\section{The first opposition: 1940-50/1990}

The years 1940-50 and the issue of age

On the right side of Figure 2 we have identified the first 20 years (1940s-50s) of American sociological production on the dimensions of temporality we considered. The semantic markers that appear are age and ages (the singular and the plural are mobilized); old age is also found in various titles. Regarding the vocabulary that refers to the assertion of scientific competence, there are several terms that emerge during the course of these years. These words emphasize the aim of comparison within the sociological domain.

Three themes of research are linked to the study of the selected temporalities. The issues of belonging and of ties appear in the theme of spatial context (national, but also residential and local) and of sexual and religious belonging within the studied groups. The titles refer to white Americans, and ignore other ethnic groups. The title of Talcott Parsons' article 'Age and Sex in the Social Structure of the United States' (1942) illustrates thus the debate on comparison in relation to key variables at a time when American quantitative sociology was in full expansion, especially with Paul Lazarsfeld's work. The (married) couple and the family are also given significant attention during the 1940s-50s with the same explanatory care, as illustrated by the article by Paul Glick and Emmanuel Landau 'Age as a Factor in Marriage' (1950). A similar trend can be noted with regard to the third significant theme: elderly people's mental health (Belknap and Friedsam, 1949).

The 1990s and the issue of the life course

On the left of Figure 2 we have identified the 1990s, a decade that stands in opposition to the 1940s-50s. The markers are different, temporal interrogation is displayed with the life course (recurrent during the course of the decade) and 


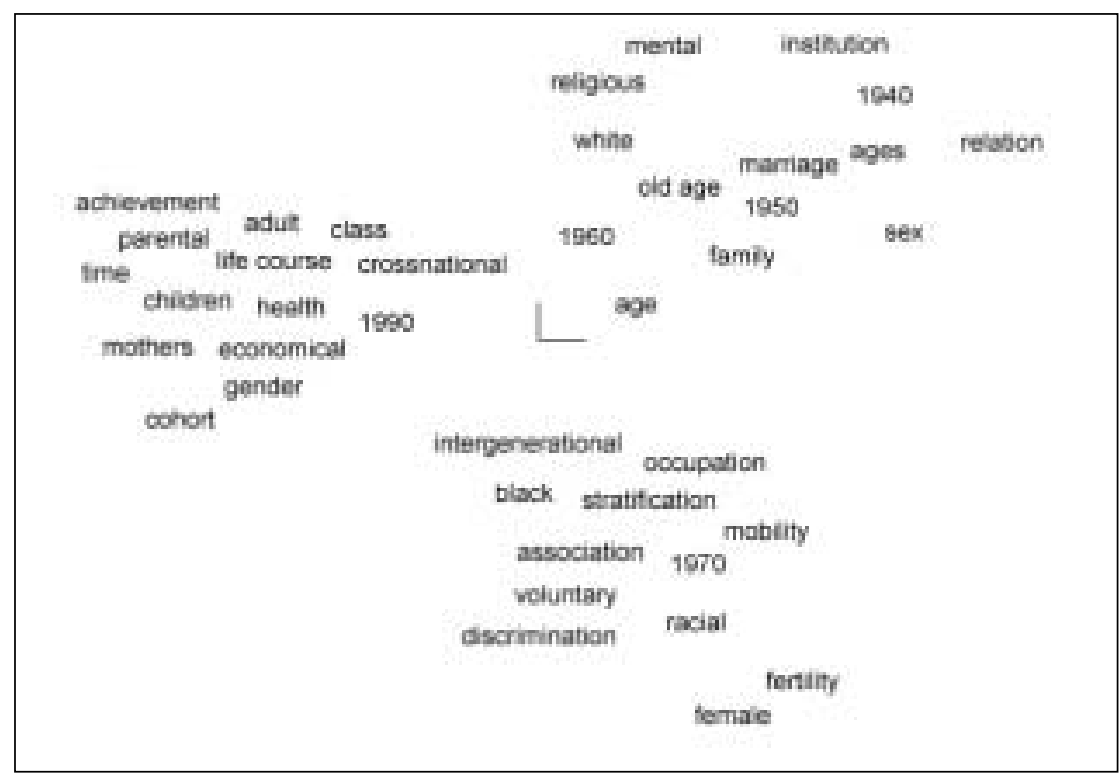

FIGURE 2

Relevant words associated with statistically significant decades

(Correspondence Analysis using the software Tri-deux 3.1)

with the adjective adult. The scientific and technical vocabularies that surround the markers always indicate the comparative aim. Stress is either on spatial or historical comparison. The titles of the articles refer to at least two international backgrounds or to the analysis of long periods of time. The comparison also relies on the analysis of cohorts, as shown in Robert O'Brien et al.'s (1999) article. Stress is also placed on the effects of the analysed phenomena (especially of the life course) and on conceptual goal, in the hope of representing specific contributions of a new theoretical perspective. ${ }^{9}$ The elaboration of new concepts sometimes demands a criticism of available works.

At a thematic level, the 1990s range across five significant fields. First of all, gender points to a shift in the approach to sexual difference, particularly when it replaces the word sex in a title (as in Steffensmeier and Streifel, 1991). Some links regarding socialization and identity, conjugal and family life and, finally, stratification and employment can be noted. Far from dealing exclusively with one theme, the titles refer, for example, to crossed interrogations on motherchild attitudes and relationships, or even on personal ordeals and the economic domain (Axinn and Thornton, 1993). Furthermore the theme of health is linked 
to the 1990s in a significant way and it is articulated around a life-course perspective (Cherlin et al., 1998).

\section{The second opposition: 1940-50/1970}

\section{The 1970s and the question of generations}

Figure 2 revealed a first opposition concerning the perspectives of age and of life course, both linked respectively to the first and to the last period of time. A second opposition also appears on the figure. Linked to the 1940s-50s, the perspective of age is secondarily opposed to reflection on the intergenerational dimension, itself linked to the 1970s and observable in the lowest part of the figure, to the right. With reference to scientific rhetoric, no real difference can be noted between the two periods, during the 1970s sociologists confined their role to the comparison and the critical commentary of already published articles.

On the thematic level, the titles of the 1970s focus on membership of groups and are especially concerned with ethnic and sexual belonging, stratification and mobility. It is well known that the consideration of potentially discriminating or unequal effects of these belongings and positions form one of the topics most widely treated by the sociological literature of the 1970s. Nearly all of the terms linked to the 1970s refer to these two thematic groups (Chase, 1975; Cherlin and Hodge, 1975). Two other significant words that also appear on the figure (attainment and fertility) seem to be isolated. A return to the titles shows once again thematic intersections that have been temporarily hidden by the Correspondence Analysis. Fertility issues are thus linked to employment and, once again, to the risk of racial discrimination (Bean and Swicegood, 1979; Hout, 1979).

\section{Contrasted Descriptions of Temporalities}

In order to draw a contrast between temporalities such as age, generation, life cycle and life course, we will henceforth consider only the strongest links between each marker and the words that surround it. The selection is achieved using a statistical index, the Pourcentage d'écart maximum (maximum percentage difference, or PEM). ${ }^{10}$ Figures 3 and 4 present the results obtained from segments representing strong links that bind words, dimensions of temporality and decades.

In Figure 3 we can see that the titles surrounding the key word age refer first of all to a particular class of age, that of elderly people. Around this dimension of temporality many efforts have been made to distinguish the effects of age, of cohort and of period. Titles exemplify this great debate. Strongly associated to the sex variable, age has been used to study the specific effects of sex at the time 


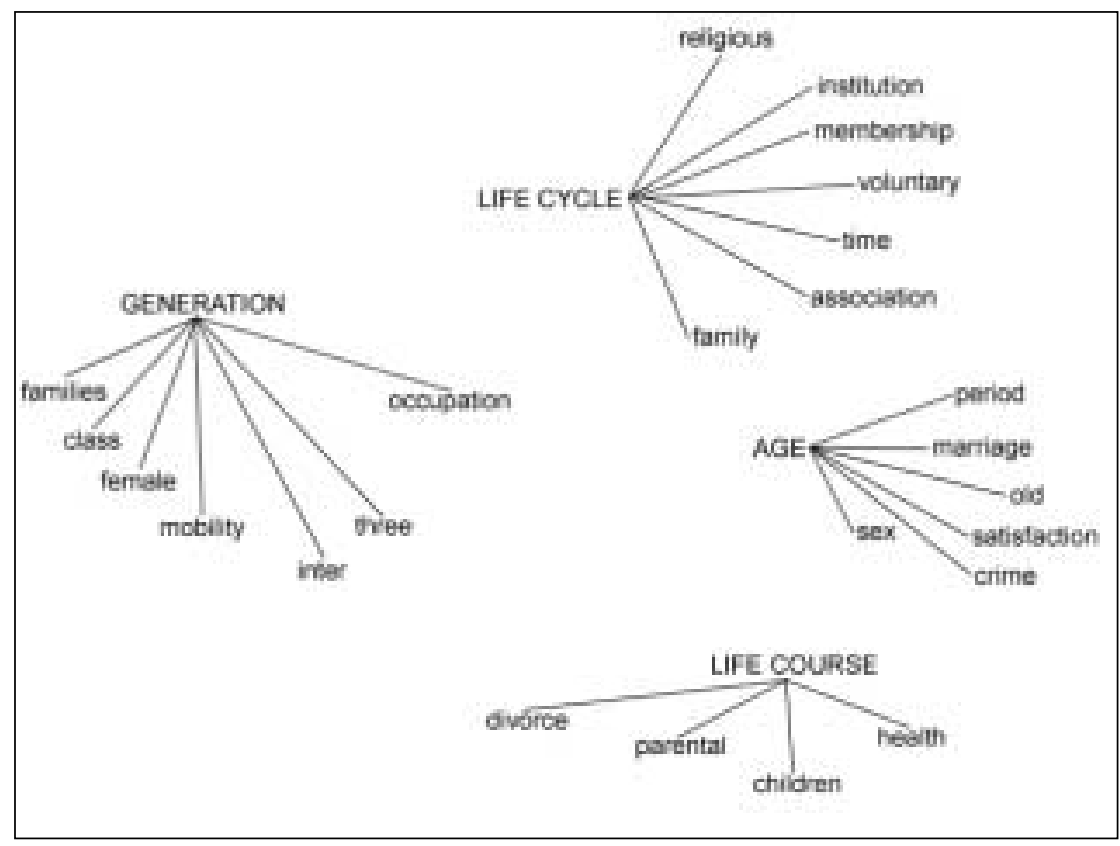

FIGURE 3

Words strongly related to the considered temporalities (software Tri-deux 3.1)

when marriage is contracted, on the distribution of crime and on variations in work satisfaction.

Titles with the marker generation display a sociology of social stratification and are concerned mostly with female professional mobility. The comparison of many generations (up to three) aims to identify behaviour patterns specific to each generation. The role played by families in passing on values or in maintaining solidarity in relationships is also stressed.

Life cycle refers to a sociology of the different stages of life within institutions: scholars therefore study voluntary associations, entrance and exit temporalities. An institution for which the life cycle has been widely used is the family. A famous syntagm that originated from this union is the family life cycle.

Life course is presented as a new perspective that pays particular attention to individual trajectories that lead individuals to face critical situations such as marital break-ups or economic difficulties. As a consequence, this raises the issue, within the domain of private life, of the relationship between parents and children, especially when the former are separated. Furthermore, it raises the 


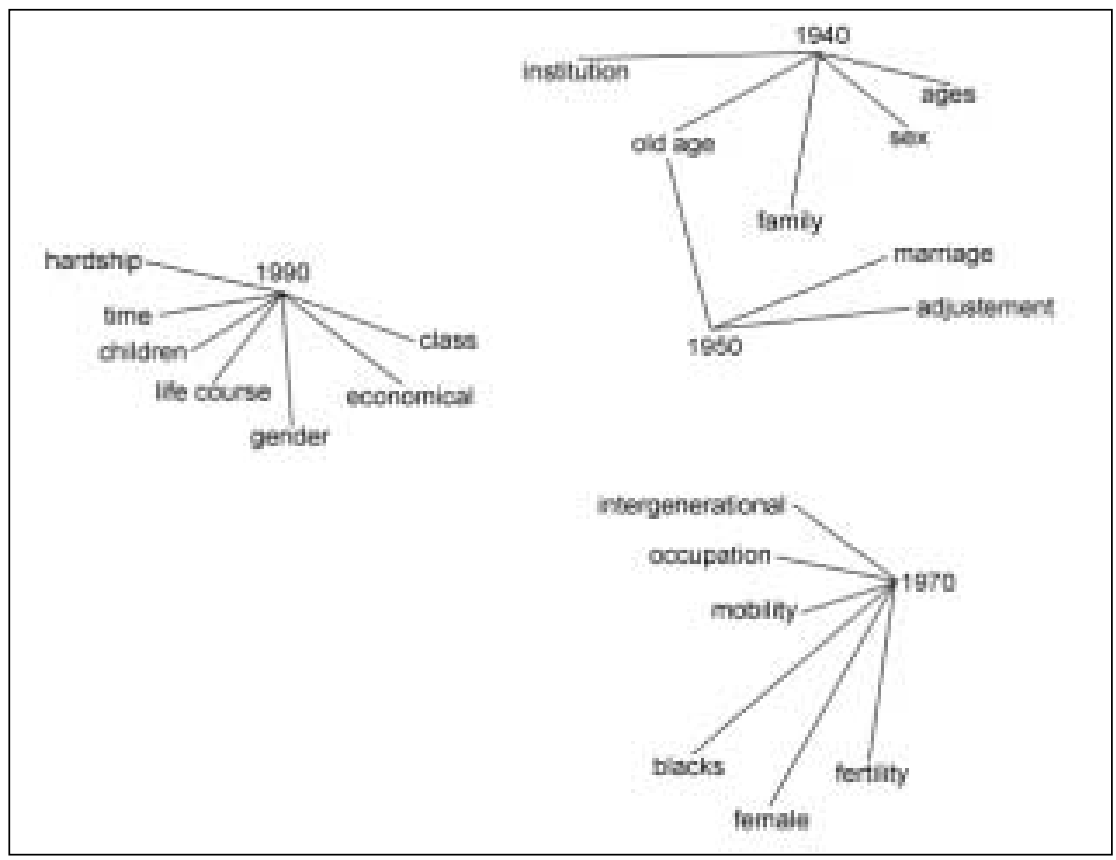

FIGURE 4

Words strongly related to statistically significant decades (software Tri-deux 3.1)

problem of the effect on individuals' health of the aforementioned ordeals. Consequently, considering the small number of titles of articles that include various semantic markers and the exclusivity of the semantic fields associated with keywords, it can be concluded that, as regards the focus chosen by the author and/or the journal, the four dimensions of temporality appear for the reader as perspectives that entail different objects of research.

The same index underlines the strong links that exist between the four decades and the words of the lexicon. In Figure 4, schematically, we can then consider the decade of the 1940s as the period of research on ages, particularly old age. With age, the sex variable assumes a great importance in the determination of behaviours in functionalist sociology. In the following decade (the 1950s), interest in elderly people remains strong and the exploration of the effects linked to age in different fields is reinforced: the study of the family is then abandoned and research focuses on age at marriage. While maintaining an approach centred on age and sex, the research now focuses on how individual behaviours adjust to the frameworks of socialization. 
Twenty years later (during the 1970s), changes are perceptible: men are differentiated from women, and for the first time references to ethnic identities appear. Social stratification becomes of paramount importance during this period, as well as the issue of professional mobility. Research then concentrates on generational approaches. By the end of the 20th century, the picture changes once again. The life course perspective is used more and more to analyse professional mobility, but above all the economic difficulties encountered by individuals. The new interest in individuals' lives is reflected in studies on private life: the stress is placed on the paths that lead individuals to end their marriages and on the consequences of divorce on children's health. From then on, the word gender will be used to refer to sexual identity.

\section{Conclusion}

This study of the American sociological literature from 1940 to 2000 teaches us many lessons. The Correspondence Analyses, based on a lexical corpus of titles of articles taken from renowned sociological journals, show that the four approaches related to the age, generation, life cycle and life course temporalities do not mobilize the same vocabulary. Each approach fits a particular period. These results provide a pride to the overall genesis of research on temporalities. At the same time they offer a contextual framework for further studies of the literature, allowing each dimension of temporality to be characterized more accurately.

First, age means different things. On the one hand, age refers to discontinuities during the course of existence. This classification allows us to differentiate childhood from adolescence, youth, adulthood and old age. Second, a strong social definition of age can be observed. It is indeed possible to associate specific institutions (such as day-care centres, youth clubs, nursing homes, colleges, high schools), behaviours and tastes with each age group. But age does not only indicate static membership of a group, it also takes into consideration individual level change since the effect of age refers to biological ageing.

The notion of the life cycle abandons the idea of linear change by trying to find some key periods in the history of groups and institutions. It has been applied to domestic life, by focusing on stages in the family cycle which lead to marriage, to childbirth and the departure of children once they grow up (Glick, 1947). Although this perspective explicitly places the emphasis on the dynamics of family life, it implicitly refers to the nuclear family pattern based on indissoluble marriage which is never preceded by cohabitation. Considering the statistically most frequent demographic transitions as necessary steps, this approach becomes the norm by focusing itself on 'the typical family' (Glick, 1947: 164). 
Influenced by works on human development and ageing, new orientations were developed in order to face this limit. This has increased the knowledge of human temporalities. In opposition to the life cycle and in a more explicit way than for age, scholars use the term life course to refer to the sequence of events within an institution and to acknowledge individual time. Going back to the example of the family, the perspective integrates the biographical transformations of the members of the domestic institution throughout life (Elder, 1977, 1987).

The aims of this approach are the complexity of individual trajectories and the meaning given to changing experiences - first love, new marital experiences and first parenting (Bengtson and Allen, 1993). More than age, the historical context of analysis of these dimensions of temporality is at the core of this approach.

The attention paid to historical time is also found in works on generations. Generations always refer to a temporal context. Starting from Karl Mannheim's (1927/1952) seminal intuitions, the generational perspective has shown that the study of the relationship between parents and children can be analysed independently of the filial tie: generation then means the time lapse that separates the parents' birth from their children's. But this perspective is also used to indicate the group of people born during the same period and who have shared important common experiences - that is what differentiates it from previous perspectives. This last element underlines the difference between belonging to a generation and other forms of social classification - based on social, professional, ethnic or sexual criteria.

\section{Notes}

1. This article is based on research funded by Caisses Nationale d'Allocations Familiales centred on the development and the significance of adolescence and youth categories in the United States, Great Britain, France and Italy between 1940 and 2000 (Cicchelli et al., 2002, 2004, 2005).

2. The titles have been identified in the databases Periodical Contents Index and the Sociological Abstract. The survey is thus exhaustive: 37 per cent of the titles are from the American Sociological Review; 30 per cent from Social Forces; 19 per cent from the American Journal of Sociology and 14 cent from Social Problems (Cicchelli et al., 2002).

3. Only 8 titles out of 259 have a double reference. Two titles indicate simultaneously age and generation; one title uses at the same time such words as age and life cycle; five titles include such words as age and life course.

4. However, only the nouns and adjectives have been retained: prepositions, adverbs, articles, pronouns and most verbs have been taken out.

5. The Correspondence Analysis presented in this article has been established from terms which appear three times or more. We would like to thank Philippe Cibois 
(University of Saint-Quentin in Yvelines) who kindly provided his Tri-deux software for the analysis.

6. As far as gender comparison is concerned, see Dejong and Brawer (1971). Regarding differences of race, see Brunswick (1970).

7. Some titles offer critical responses to previously published articles (Smith et al., 1982).

8. Several tests were carried out in various periods. However, relevant analysis was obtained only within decades.

9. On this point, Eliza Pavalko and Glen Elder offer a good example in 'World War II and Divorce: A Life Course Perspective' (1990).

10. The maximum percentage difference (PEM) estimates the strength of the links. In the figures, we have retained values above 10 per cent (see Cibois, 1993).

\section{References}

Axinn, W. and Thornton, A. (1993) 'Mothers, Children and Cohabitation: The Intergenerational Effects of Attitudes and Behavior', American Sociological Review 58(2): 233-46.

Bean, F. and Swicegood, G. (1979) 'Intergenerational Occupational Mobility and Fertility: A Reassessment', American Sociological Review 44(4): 608-19.

Belknap, I. and Friedsam, H. (1949) 'Age and Sex Categories as Sociological Variables in the Mental Disorders of Later Maturity', American Sociological Review 14(3): 367-76.

Bengtson, V. L. (1975) 'Generation and Family Effects in Value Socialization', American Sociological Review 40(3): 358-71.

Bengtson, V. L. and Allen, K. R. (1993) 'The Life Course Perspective Applied to Families Over Time', in P. G. Boss et al. (eds) Sourcebook of Family Theories and Methods. A Contextual Approach, pp. 469-99. New York: Plenum Press.

Benney, M., Riesman, D. and Star, S. A. (1956) 'Age and Sex in the Interview', American Journal of Sociology 62(2): 143-52.

Bergmann, W. (1992) 'The Problem of Time in Sociology. An Overview of the Literature on the State Theory and Research on the "Sociology of Time". 1900-82', Time \& Society 1(1): 81-134.

Brunswick, A. F. (1970) 'What Generation Gap? A Comparison of Some Generational Differences among Blacks and Whites', Social Problems 17(3): 358-71.

Chase, I. (1975) 'A Comparison of Men's and Women's Intergenerational Mobility in the United States', Social Forces 54(1): 194-8.

Cherlin, A. J. and Hodge, R. (1975) 'Age, Adjustment of Racial Income Differences: A Research Note', American Sociological Review 40(4): 483-505.

Cherlin, A. J., Chase-Lansdale, P. L. and McRae, C. (1998) 'Effects of Parental Divorce on Mental Health throughout the Life Course', American Sociological Review 63(2): 239-49.

Cibois, P. (1993) 'Le PEM, pourcentage de l'écart maximum: un indice de liaison entre modalités d'un tableau de contingence', Bulletin de Méthodologie Sociologique 40: 43-63.

Cicchelli, V., Pugeault-Cicchelli, C. and Merico, M. (2002) Les mots pour le dire. 
Généalogie des catégories d'adolescence et de jeunesse aux Etats-Unis, en Grande Bretagne, en France et en Italie (1940-2000). Paris: CNAF.

Cicchelli, V., Pugeault-Cicchelli, C. and Merico, M. (2004) 'Age, generation, life cycle and life course dans les titres d'articles sociologiques américains: 1940-2000', Temporalités (dossier Générations) 2: 89-106.

Cicchelli, V., Pugeault-Cicchelli, C. and Merico, M. (2005) 'Le rappresentazioni del giovane e dell'adolescente nelle riviste di sociologia (dal 1940 al 2000)', Africa e Mediterraneo 51-2: 78-81.

Dejong, P. Y. and Brawer, M. J. (1971) 'Patterns of Female Intergenerational Occupational Mobility: A Comparison with Male Patterns of Intergenerational Occupational Mobility', American Sociological Review 36(6): 1033-42.

Demos, J. and Demos, V. (1969) 'Adolescence in Historical Perspective', Journal of Marriage and the Family 31: 632-8.

Dubas, J. S., Miller, K. and Petersen, A. C. (2003) 'The Study of Adolescence during the 20th Century', The History of the Family 8: 375-97.

Elder, G. (1977) 'Family History and the Life Course', Journal of Family History 2: 279-304.

Elder, G. (1987) 'Families and Lives: Some Developments in Life-course Studies', in T. Hareven and A. Plakans (eds) Family History at the Cross-roads, pp. 179-99. Princeton, NJ: Princeton University Press.

Furstenberg, F. Jr., Nord, C. W., Peterson, J. L. and Zill, N. (1983) 'The Life Course of Children of Divorce: Marital Disruption and Parental Contact', American Sociological Review 48(5): 656-68.

Galland, O. (1991) Sociologie de la jeunesse. Paris: Armand Colin.

Glenn, N. (1976) 'Cohort Analysts' Futile Quest: Statistical Attempts to Separate Age, Period and Cohort Effects', American Sociological Review 41(5): 900-4.

Glick, P. C. (1947) 'The Family Cycle', American Sociological Review 12(2): 164-74.

Glick, P. and Landau, E. (1950) 'Age as a Factor in Marriage', American Sociological Review 15(4): 517-29.

Goyder, J. C. and Curtis, J. E. (1975) 'A Three-generational Approach to Trends in Occupational Mobility', American Journal of Sociology 81(1): 129-38.

Hindelang, M. J. (1971) 'Age, Sex, and the Versatility of Delinquent Involvements', Social Problems 18(4): 522-35.

Hout, M. (1979) 'Age, Structure, Unwanted Fertility and the Association between Racial Composition and Family Planning Programs: A Comment on Wright', Social Forces 57(4): 1387-92.

Kett, J. (2003) 'Reflections on the History of Adolescence in America', The History of the Family 8(3): 355-73.

Knoke, D. and Thomson, R. (1977) 'Voluntary Association Membership Trends and the Family Life Cycle', Social Forces 56(1): 48-65.

Lansing, J. B. and Kish, L. (1957) 'Family Life Cycle as an Independent Variable', American Sociological Review 22(5): 512-19.

Lee, Y. J., Parish, W. L. and Willis, R. J. (1994) 'Sons Daughters, and Intergenerational Support in Taiwan', American Journal of Sociology 99(4): 1010-41.

Leslie, G. R. (1961) 'Life-cycle, Career Pattern, and the Decision to Move', American Sociological Review 26(6): 894-902.

Lowrie, S. H. (1952) 'Sex Differences and Age of Initial Dating', Social Forces 30(4): 456-61. 
Mannheim K. (1927/1952) 'The Problem of Generation', in K. Mannheim Essays on the Sociology of Knowledge, pp. 276-322. London: Routledge and Kegan Paul.

Mirowsky, J. and Ross, C. E. (1999) 'Economic Hardship Across the Life Course', American Sociological Review 64(4): 548-69.

Moen, P., Dempster-McClain, D. and Williams, R. (1992) 'Successful Aging: A Lifecourse Perspective on Women's Multiple Roles and Health', American Journal of Sociology 97(6): 1612-38.

Mounin, G. (1973) Vocabulaire de la linguistique. Paris: PUF.

O'Brien, R., Stockard, J. and Isaacson, L. (1999) 'The Enduring Effects of Cohort Characteristics on Age-specific Homicide Rates, 1960-1995', American Journal of Sociology 104(4): 1061-95.

Palmore, E. (1978) 'When Can Age, Period, and Cohort Be Separated?', Social Forces 57(1): 282-95.

Parsons, T. (1942) 'Age and Sex in the Social Structure of the United States', American Sociological Review 7(5): 604-16.

Pavalko, E. and Elder, G. (1990) 'World War II and Divorce: A Life Course Perspective', American Journal of Sociology 95(5): 1213-34.

Rotolo, T. (2000) 'A Time to Join, a Time to Quit: The Influence of Life Cycle Transitions on Voluntary Association Membership', Social Forces 78(3): 1133-61.

Saraceno, C. (1986) 'Introduzione', in C. Saraceno (ed.) Età e corso della vita, pp. 7-26. Bologna: Il Mulino.

Smith, H., Mason, W. and Fienberg, S. (1982) 'More Chimeras of the Age-PeriodCohort Accounting Framework: Comment on Rodgers', American Sociological Review 47(6): 787-93.

Steffensmeier, D. and Streifel, C. (1991) 'Age, Gender and Crime Across Three Historical Periods', Social Forces 69(3): 869-94.

Stolzenberg, R. M., Blair-Loy, M. and Waite, L. J. (1995) 'Religious Participation in Early Adulthood: Age and Family Life Cycle Effects on Church Membership', American Sociological Review 60(1): 84-103.

Thomas, M. E., Herring, C. and Horton, H. D. (1994) 'Discrimination over the Life Course: A Synthetic Cohort Analysis of Earnings Differences between Black and White Males (1940-1990)', Social Problems 41(4): 608-28.

Treas, J. and Widmer, E. D. (2000) 'Married Women's Employment over the Life Course: Attitudes in Cross-national Perspective', Social Forces 78(4): 1409-36.

VINCENZO CICCHELLI is Maître de Conférences at the Faculté des Sciences Humaines et Sociales, Université René Descartes, Paris VSorbonne, and Research Fellow at the Centre de Recherches sur les Liens Sociaux (CNRS, Paris Descartes). He works on the history of the sociology of adolescence and youth, youth citizenship and social participation, adolescents and their relationship with civil society in Mediterranean countries. Among his publications is La construction de l'autonomie (2001). ADDRESS: Cerlis, Paris Descartes/CNRS, 45 rue des Saints-Pères, 75270 Paris Cedex 06, France.

[email: vincenzo.cicchelli@paris5.sorbonne.fr] 
CATHERINE PUGEAULT-CICCHELLI is Maitre de Conférences at the Faculté des Sciences Humaines et Sociales, Université René Descartes, Paris V-Sorbonne, and Research Fellow at the Centre de Recherches sur les Liens Sociaux (CNRS, Paris Descartes). She works on the history of the sociology of the family, adolescence and youth, marriage, coupling, conjugal rituals in contemporary societies. Among her publications is Ce que nous savons des jeunes (edited with Vincenzo Cicchelli and Tariq Ragi, 2004). ADDRESS: Cerlis, Paris Descartes/CNRS, 45 rue des Saints-Pères, 75270 Paris Cedex 06, France.

[email: catherine.cicchelli-pugeault@paris5.sorbonne.fr]

MAURIZIO MERICO is Research Fellow at the Department of Sociology and Political Science, University of Salerno, Italy. He works on the history of the sociology of youth, young people in contemporary society, youth citizenship and culture and religion in Southern Italy. In 2005 he attended the Fulbright American Study Institute on 'Religion in the US: Pluralism and Public Presence' at the University of California (Santa Barbara). Among his publications is Giovani e società (2004). ADDRESS: Dipartimento di Sociologia e Scienza della Politica, Università di Salerno, via Ponte don Melillo, 84084 Fisciano (SA), Italy.

[email: merico@unisa.it] 